Invited Editorial

\title{
Indonesia national health policy in the transition of disease burden and health insurance coverage
}

\author{
Nila F. Moeloek
}

Minister of Health, Republic of Indonesia, Jakarta, Indonesia

Nowadays, Indonesia is struggling to deal with the challenges of triple burden of diseases, i.e., noncommunicable diseases (NCDs), communicable diseases, and the existing but neglected tropical diseases, such as yaws, schistosomiasis, and other emerging and reemerging diseases.

The etiology of all those diseases is multifactorial. In the 1990s, the leading causes of mortality and morbidity are infectious diseases, such as upper respiratory tract infection, tuberculosis (TB), diarrhea, etc. With the high rates of urbanization the possibility of TB transmission in healthy population became greater. The use of facial mask did not prove to prevent TB transmission effectively. Tuberculosis bacteria can spread up to 30 centimeters via large particle droplets during coughing. Furthermore, we are still at risk of suffering dengue fever, caused by Aedes Aegypti mosquito bites --- a health problem familiar to Indonesia, but which has not been resolved comprehensively.

Since 2010, the leading causes of mortality and morbidity in Indonesia have been dominated by the non-communicable disease (NCDs), such as stroke, heart diseases, and diabetes mellitus. The National Health Insurance (NHI), which was established in 2014, is expected to provide opportunity for low-income families to afford access to health-care services. As mandated by the Law, the Government of Indonesia must borne the cost of premium for $40 \%$ of the poorest, poor and near poor of the population. To date, the government has covered the premium cost of 92.4 million people. In addition to that, another 70 million people paid independently to a total of 170 million people now insured under the NHI.

It is expected that by 2019 the NHI will cover 100 percent of the Indonesian population, which means that by that time Universal Health Coverage will be fulfilled in the true sense of the word. As coverage of the NHI continues to expand, more and more people, particularly those of the lowincome groups; have gained access to health care.

\section{Current disease patterns}

The current landscape of disease patterns in Indonesia shows that the NCDs have increasingly shifted from older to the younger age, and cut across all socio-economic classes. These diseases are, for the most part, associated with unhealthy diet. Yet, the current situation also shows that more and more people in the rural areas have hypertension and diabetes mellitus, which may be associated with some pre-existing conditions, such as prenatal malnutrition. These pre-existing conditions may serve as a predisposing factor for developing the NCDs later in life.

When a family member suffers from one of the NCDs, it is obvious that he or she will need a long-term medical treatment. This will without a doubt, lead to the increased financial burden both on the government and on the community members themselves. It will also decrease his or her productivity and will in turn put an enormous strain on the economic condition of the family. The patient, or the family affected, may slip into poverty because of the financial resources and the prolonged period of time spent for the treatment. Based on the national data, the NCDs have become catastrophic diseases that absorb one-third of the expenditure for the NHI.

It should be understood that our health condition is rooted in our behavior or lifestyles. In the past, our health paradigm was oriented toward improving health quality by attempting to cure a disease, rather than preventing it from happening. However, curing a disease through medical treatment has proven to be considerably more expensive than prevention. 
For example, in this NHI era, in order to cover the medical costs of hemodialysis for a renal failure patient, it requires the equivalent amount of insurance for 40 healthy people. Meanwhile, there are many ways to prevent a person from developing renal failure. Today, the more advanced people are, the easier for them to have access to the current information. In addition, the increased use of transportation has changed people's lifestyle. Following are the examples of the NCDs related to the changing lifestyles of the people:

- People are less active. They are more likely to spend more time watching TV, playing games, and sitting too long in front of the computer screen. This can increase the risk of obesity;

- Changes in diet. People now have tendency to eat processed foods, ready-to-eat foods which are high in sugar, salt and fat, and less high fiber foods, such as fruit and vegetables. This causes indigestion;

- Alcohol consumption. It causes organ damage and increase the risk of death;

- Smoking. It causes various diseases, including lung cancer, oral cancer, etc;

- Contaminated environment, for example open defecation. Currently, there are around 63 million people still defecating in rivers, lakes, sea, and land. Indiscriminate defecation may cause abdominal pain and diarrhea, as well as other diseases.

\section{GERMAS, promotive-preventive, and family- based approaches}

Because of the changes in the pattern of national disease burden, associated with changes in human behavior and the rapid population growth over the last 30 years, it is imperative to set up a national program to improve people's health quality.

Although the Ministry of Health has developed and implemented a roadmap to achieve a healthy society, it needs to work closely with other ministries and institutions in order to be able to reduce the prevalence of diseases and mitigate their impacts. Furthermore, it requires a cross-sector collaboration with various relevant organizations.

Therefore, President of Indonesia enacted a national regulation, i.e., Presidential Instruction No $1 / 3027$, for a national health program, called Gerakan Masyarakat Hidup Sehat (GERMAS -
Community Movement for Healthy Life). This program aims to guide national health policy and achieve health-oriented development.

GERMAS activities are directed to align with other sectors in health development in order to encourage people to live a healthy life in a comprehensive manner, from the central level to the community level, which is the ultimate goal of this program. The declaration of GERMAS was carried out by the Coordinating Minister of Human Development and Culture, Mrs. Puan Maharani together with other Ministers of the Working Cabinet on November 15, 2016 in 10 places in Indonesia. GERMAS is coordinated by the Ministry of National Development Planning (BAPPENAS) and represents a collective action among ministries, institutions and partners with a strong cross-sector approach. GERMAS covers a number of basic principles underlying its activities, i.e.:

Focus on equitable intervention. Efforts to reduce the burden of disease is focused on social determinant-related diseases such as poverty, gender, environment, and others.

Collaboration between different sectors and stakeholders. Strengthening cooperation between health sector and other government sectors and stakeholders, civil society, academia, private sector in controlling communicable and non-communicable diseases.

Balanced relationship in the life of community, family and individual. Interventions to control the risk factors of diseases are implemented at the community level as well as in high-risk individual.

Community empowerment. Disease control initiatives are strengthened through community's empowerment, involving those who are committed to healthy lifestyle and become partners in controlling diseases.

Strengthening health systems. Strengthening the reformation and quality of primary health care system as an effort to strengthen promotivepreventive health services.

The life-cycle approach. Disease control is carried out in all parts of the life cycle, starting from the health of pregnant women, fetus, infant, adolescent, adult to elderly. 
In line with the implementation of the National Health Insurance (NHI) efforts are made to ensure that all people have access to health services, including health-care services for disease prevention.

The strategy or action plan that is based on evidence. Planning and strategy in GERMAS is carried out based on data and facts that originate from the community.

\section{GERMAS and other supporting programs}

GERMAS program differs from other national health programs in the sense that the former aims to optimize the existing health programs using facilities and infrastructure with the relevant ministries, rather than create an entirely new program.

One of the concrete cross-sector supports for the success of GERMAS is Program Infrastruktur Berbasis Masyarakat (IBM, or Community-Based Infrastructure Program) implemented by Ministry of Public Works and Housing. This program focuses on developing access to drinking water, sanitation, and proper housing, which are the foundation to support hygienic and healthy lifestyles. Another important support comes from Badan Pengawas Obat dan Makanan (BPOM, Food and Drug Administration) in terms of food safety. Furthermore, Ministry of Health and local health authorities are committed to supporting GERMAS program by:

- Applying Minimum Health Service Standards, which was issued by the Ministry of Internal Affairs in 2017, and has become a health indicator for local government. These standards will guide local government in providing basic health services.

- Actively pursuing collaborations with local health authorities to carry out familiarization of the program, provide sustainable assistance and advocacy and implement GERMAS in provinces, districts/ cities by actively involving citizens.

Closely linked with GERMAS as a cross-sector program is the Community Health Center (Puskesmas) which serves as a gate-keeper to prevent community members from falling ill and ensure that they have access to early detection and treatment. Strengthening and increasing the quality of primary health care is indispensable in terms of infrastructure, human resources and proactive actions in providing health-care services for communities, particularly family as the smallest unit of the community.

Therefore, the Ministry of Health puts a strong focus on the efforts to reach out to the families to ensure that they could benefit from health-care services through family-based approach. At the primary health care level, family supervisors are assigned to carry out counseling, educate, and motivate people to seek treatment when they get sick. The tasks also include collecting data of the family health, including data on the environment, and even their working conditions, that require special attention.

To achieve this goal, health provider at primary care level should be competent as a technical officer to treat people, and must master the technical and clinical skills required to solve and treat patients at the center instead of directly referring them to hospitals.

To optimize all the efforts, primary health centers such as Pos Pelayanan Terpadu (Posyandu -Integrated Health-care Post), Pondok Bersalin Desa (Polindes - Village Maternity Clinic) or Pos Binaan Terpadu Penyakit Tidak Menular (Posbindu-PTM -- Integrated Partnership Clinic of Non-Communicable Diseases) are established in the areas between families and Puskesmas and hospitals. These institutions provide a more direct access for families and community members. Such relatively easy access will make it possible for them to benefit from early detection program and increase their awareness of disease prevention initiatives.

Through GERMAS, Ministry of Health also collaborates with the Ministry of Village, Development of Disadvantaged Areas and Transmigration provides one house, termed "Health Village House" or Rumah Desa Sehat; in a designated local area to serve as intermediate health centers.

GERMAS encourages people to practice a healthy lifestyle by abandoning unhealthy lifestyles. In order to do this successfully, GERMAS puts emphasis on:

- Physical activities and exercises, which can be carried out collectively in the local area; 
- Encouraging people to eat healthy food, vegetables and fruit which could be planted in their own backyards;

- Regular health check-up at Posbindu. Family members with hypertension or diabetes mellitus could be early detected and referred to the health center for treatment, if necessary.

Ministry of Health hopes that people from all walks of life will be able to participate in ensuring the success of the GERMAS program. Academia is expected to actively introduce the program of health development to achieve health community in their teaching subjects and to familiarize this program among their students. As research and teaching centers, universities can also become think tanks for policy implementation.

The Joint Decree of the Ministry of Research, Technology and Higher Education and the Ministry of Health stated that Academic Health System (AHS) is a collaboration between the health-care services and medical school teaching hospitals. AHS aims to enhance the effectiveness and efficiency of the two institutions in providing health services to the community. This system endorses the integration of a variety of research and medical educations to produce high-quality health services based on the local conditions. That way, researchers and clinicians will be able to enhance GERMAS in an integrated manner in order to ensure its benefits for every person in Indonesia.

As one of the Indonesian journals that has been indexed as an international journal (Scopus), Medical Journal of Indonesia (MJI) has the obligation to contribute for the health of the people of Indonesia. The updated information in the scientific study can expand the knowledge in the health sector and encourage the creation of new breakthroughs to deal with health problems, which can be applied in GERMAS. Furthermore, through MJI and Scopus, GERMAS can be socialized extensively, both within Indonesia and overseas, and may gain a positive feedback for the evaluation and improvement of the program.

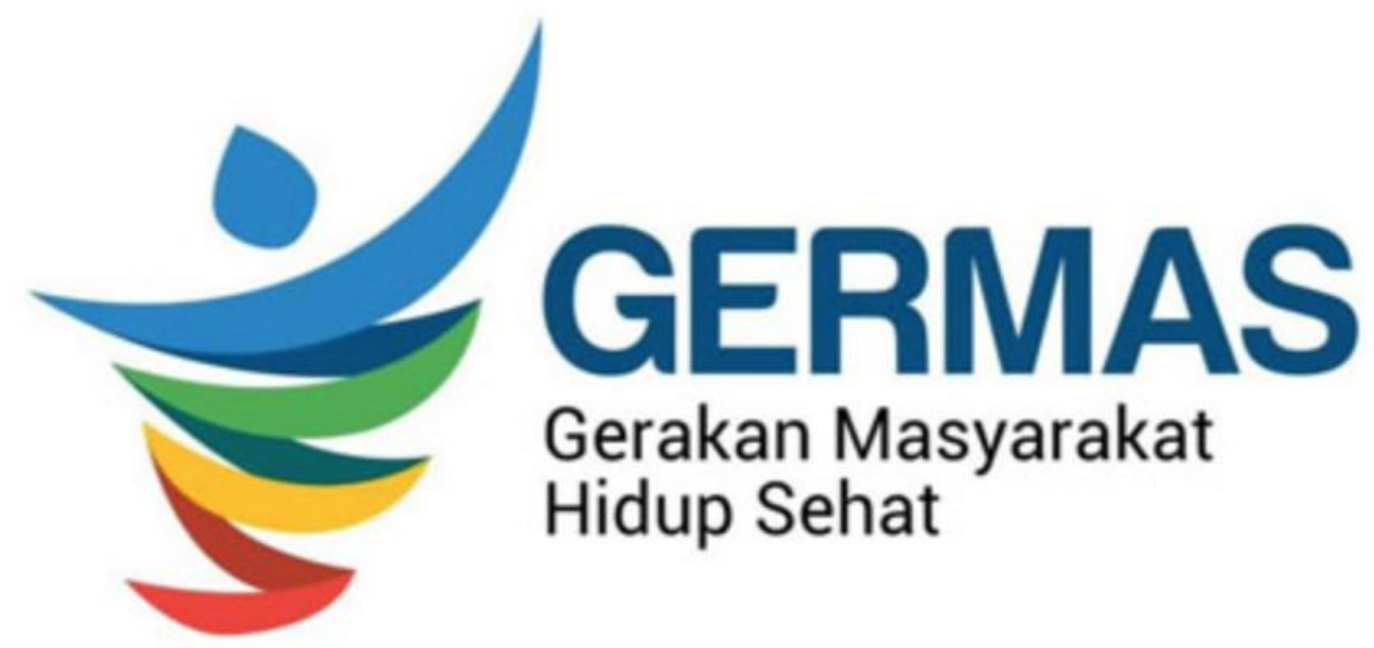

pISSN: 0853-1773 • eISSN: 2252-8083 • http://dx.doi.org/10.13181/mji.v26i1.1975• Med J Indones. 2017;26:3-6

Corresponding author: Nila F. Moeloek, nilafmoeloek@gmail.com

Copyright @ 2017 Authors. This is an open access article distributed under the terms of the Creative Commons Attribution-NonCommercial 4.0 International License (http://creativecommons.org/licenses/by-nc/4.0/), which permits unrestricted non-commercial use, distribution, and reproduction in any medium, provided the original author and source are properly cited. 